\title{
Impact of non-neurological complications in severe traumatic brain injury outcome
}

\author{
Luisa Corral ${ }^{1,2^{*}}$, Casimiro F Javierre ${ }^{2}$, Josep L Ventura ${ }^{1}$, Pilar Marcos ${ }^{3}$, José I Herrero ${ }^{1}$ and Rafael Mañez ${ }^{1,4}$
}

\begin{abstract}
Introduction: Non-neurological complications in patients with severe traumatic brain injury (TBI) are frequent, worsening the prognosis, but the pathophysiology of systemic complications after TBI is unclear. The purpose of this study was to analyze non-neurological complications in patients with severe TBI admitted to the ICU, the impact of these complications on mortality, and their possible correlation with TBI severity.

Methods: An observational retrospective cohort study was conducted in one multidisciplinary ICU of a university hospital (35 beds); 224 consecutive adult patients with severe TBI (initial Glasgow Coma Scale (GCS) < 9) admitted to the ICU were included. Neurological and non-neurological variables were recorded.

Results: Sepsis occurred in $75 \%$ of patients, respiratory infections in $68 \%$, hypotension in $44 \%$, severe respiratory failure (arterial oxygen pressure/oxygen inspired fraction ratio $\left.\left(\mathrm{PaO}_{2} / \mathrm{FiO}_{2}\right)<200\right)$ in $41 \%$ and acute kidney injury (AKI) in $8 \%$. The multivariate analysis showed that Glasgow Outcome Score (GOS) at one year was independently associated with age, initial GCS 3 to 5, worst Traumatic Coma Data Bank (TCDB) first computed tomography (CT) scan and the presence of intracranial hypertension but not AKI. Hospital mortality was independently associated with initial GSC 3 to 5, worst TCDB first CT scan, the presence of intracranial hypertension and AKI. The presence of AKI regardless of GCS multiplied risk of death 6.17 times (95\% confidence interval (CI): 1.37 to 27.78) $(P<0.02)$, while ICU hypotension increased the risk of death in patients with initial scores of 3 to 5 on the GCS 4.28 times (95\% Cl: 1.22 to 15.07$)(P<0.05)$.

Conclusions: Low initial GCS, worst first CT scan, intracranial hypertension and AKI determined hospital mortality in severe TBI patients. Besides the direct effect of low GCS on mortality, this neurological condition also is associated with ICU hypotension which increases hospital mortality among patients with severe TBI. These findings add to previous studies that showed that non-neurological complications increase the length of stay and morbidity in the ICU but do not increase mortality, with the exception of AKI and hypotension in low GCS (3 to 5).
\end{abstract}

\section{Introduction}

Severe Traumatic Brain Injury (TBI) mortality and morbidity is frequently caused by the neurological consequences of the brain injury [1,2]. Nevertheless, nonneurological complications are also frequent, and may be cardiovascular, respiratory, infectious and others [3-5]. An initial study by Zygun et al. showed that nonneurological organ dysfunction measured by Sequential Organ Failure Assessment (SOFA) was not associated with increased mortality in neurocritical patients with TBI or subarachnoid hemorrhage, despite the frequent

\footnotetext{
* Correspondence: Icorral@bellvitgehospital.cat

'Intensive Care Unit, Hospital Universitari de Bellvitge, Feixa Llarga s/n,

L'Hospitalet de Llobregat-08907, Barcelona, Spain

Full list of author information is available at the end of the article
}

finding of cardiopulmonary dysfunction [6]. However, a later study by the same group associated non-neurological organ dysfunction with worse outcome, reporting that cardiovascular and respiratory complications were the most common dysfunctions [5].

The pathophysiology of systemic complications after TBI is unclear. Complications may arise from the direct effect of the injury or as a result of the side effects of therapy $[7,8]$. Neurogenic causes such as the massive catecholamine and neuro-inflammatory response associated with brain injury may contribute to systemic complications. In addition, the intensive care management of TBI patients is mainly directed at neurological problems and may contribute to non-neurological complications [8].

\section{Biomed Central}


A better knowledge of the incidence, causes and consequences of non-neurological complications in patients with severe TBI would help in their prevention, treatment and prognosis. The purpose of this study was to analyze the non-neurological complications presented by patients with severe TBI admitted to the ICU, the impact of these complications on hospital mortality and outcome at one year, and their possible correlation with TBI severity.

\section{Materials and methods}

The study included 224 adult patients with severe TBI (initial Glasgow Coma Scale (GCS) < 9), consecutively admitted to the ICU, between 1998 and 2004. It is an observational retrospective cohort study. The initial GCS score was obtained upon admission to the emergency ICU. If the patient was already intubated and on mechanical ventilation the previous GCS score was used and GCS scale was divided into two levels of severity: low (GCS 3 to 5) and high (GCS 6 to 8) $[9,10]$. The study was approved by the institution's Research Ethics Committee, which did not consider informed consent to be necessary because of the study design. Management of patients followed international guidelines [11], with the goal of maintaining a cerebral perfusion pressure (CPP) of 60 to $70 \mathrm{mmHg}$ and an intracranial pressure (ICP) of $<20 \mathrm{mmHg}$. Intracranial hypertension was defined as ICP $>20 \mathrm{mmHg}$ for 15 minutes without a systemic cause. Elevations in ICP were managed sequentially with sedation, paralysis, mannitol and mild hyperventilation. Barbiturate therapy was considered for refractory intracranial hypertension. The therapy index [12] was used to quantify the treatment for intracranial hypertension that was enough to quantify the treatments used in that year following international guidelines. Computerized tomography (CT) of the brain at admission was evaluated following the Traumatic Coma Data Bank Computed Tomography (TCDB CT) scan classification. Mortality at hospital discharge and Glasgow Outcome Scale (GOS) at one year was obtained and was dichotomized as worse outcome (dead, vegetative state and severe disability) and as good outcome (moderate disability and good recovery) [9].

The following non-neurological complications were recorded:

Cardiovascular: ICU hypotension (systolic blood pressure $(\mathrm{SBP})<90 \mathrm{mmHg}$ for 30 minutes during the ICU stay), hypertension (SBP $>160 \mathrm{mmHg}$ for more than 30 minutes and, in hypertensive subjects, an increase $>40$ $\mathrm{mmHg}$ that required treatment change [3]), cardiac arrhythmias (bradycardia $<60$ beats/minute or tachycardia $>120$ beats/minute) and the need for vasoactive drugs (dopamine, dobutamine or norepinephrine).
Respiratory: infectious respiratory complications (aspiration, tracheobronchitis or pneumonia (infiltrate on chest radiograph and analysis of gram or sputum culture-positive [3])), acute respiratory distress syndrome (ARDS) [13], $\mathrm{PaO}_{2} / \mathrm{FiO}_{2}$ ratio 200 to 300 and severe respiratory failure (SRF) as $\mathrm{PaO}_{2} / \mathrm{FiO}_{2}$ ratio < 200.

Septic: severe sepsis [14] and septic shock [14].

Renal: acute kidney injury (AKI) (serum creatinine > $150 \mu \mathrm{mol} / \mathrm{L}$ ) with or without dialysis [3].

Abdominal/digestive complications: ileus, cholecystitis, bilirubin levels $>18 \mu \mathrm{mol} / \mathrm{L}$ and aspartate amino transferase $($ AST) $>1 \mu \mathrm{kat} / \mathrm{L}[3]$.

Endocrinometabolic: hyponatremia $<130 \mathrm{mmol} / \mathrm{L}$, hypernatremia $>150 \mathrm{mmol} / \mathrm{L}$, syndrome of inappropriate antidiuretic hormone secretion $(\mathrm{SIADH})(\mathrm{Na}<130$ $\mathrm{mmol} / \mathrm{L}$, urine osmolality exceeding serum osmolality [3]), cerebral salt wasting syndrome (excessive diuresis with urine sodium below $>20 \mathrm{mmol} / \mathrm{L} \mathrm{[15])} \mathrm{and} \mathrm{dia-}$ betes insipidus (diuresis $>200 \mathrm{~mL} /$ hour for 24 hours without response to fluid restriction or needing treatment with desmopressin, urine specific gravity $<1,005$ and a urine osmolality less than half that of plasma).

Bleeding: hemorrhage needing blood transfusion products (> 4 packed cells) and/or hemorrhagic shock during ICU admission.

\section{Statistical analysis}

Continuous variables (age, ICU stay and in hospital stay) were expressed as median and interquartile range. Categorical data were expressed as frequency and percentage. We used the chi square test to compare categorical data and proportions, and the T-test, MannWhitney test or Kruskal-Wallis, as appropriate, to compare continuous variables. Multivariate analysis was performed with multivariate regression and variables were selected using either the stepwise or the backward regression procedures. Confounding and interaction variables were studied, and the effect size on outcome was calculated for clinical complications during the ICU stay, as well as the effect size on ICU hypotension. An alpha level of 0.05 was used to determine statistical significance. All data in the present study were analyzed using SPSS version 16.0 (SPSS Inc, Chicago, USA).

\section{Results}

The characteristics of the sample are shown in Table 1 $[9,16]$. ICP was monitored in $73 \%$ of the patients $(n=$ $164), 51 \%(n=83)$ of whom developed intracranial hypertension and $56 \%$ low cerebral perfusion pressure at some point in the evolution of their condition. Hypoxia at admission was detected in 64 patients, it was not detected in 152 and 8 had missing data. Hypotension at admission was detected in 38 patients. The median 
Table 1 Clinical characteristics of 224 patients with severe traumatic brain injury.

\begin{tabular}{|c|c|c|}
\hline & & No. (\%) \\
\hline & & 224 \\
\hline Age (median, interquartile re & & $35.6(23-55)$ \\
\hline Gender & Male & $189(84)$ \\
\hline & Female & $35(16)$ \\
\hline Mechanism of injury & Traffic accident & $148(66)$ \\
\hline & Falls & $58(26)$ \\
\hline & Assault & $6(3)$ \\
\hline & Others & $12(5)$ \\
\hline Multiple trauma & & $127(57)$ \\
\hline GCS & 3 & $30(13)$ \\
\hline & 4 & $35(16)$ \\
\hline & 5 & $30(13)$ \\
\hline & 6 & $40(18)$ \\
\hline & 7 & $35(16)$ \\
\hline & 8 & $54(24)$ \\
\hline & Low GCS (GCS 3, 4, 5) & $95(42)$ \\
\hline & High GCS (GCS 6, 7, 8) & $129(58)$ \\
\hline TCDB CT scan classification & । & $14(6)$ \\
\hline & $\|$ & $120(54)$ \\
\hline & III & $26(12)$ \\
\hline & IV & $21(9)$ \\
\hline & EM & $38(17)$ \\
\hline & NEM & $5(2)$ \\
\hline & I, II, EM & $172(77)$ \\
\hline & III, IV, NEM & $52(23)$ \\
\hline Detected hypotension at ad & ion & $38(17)$ \\
\hline Detected hypoxia at admiss & & $64(29)$ \\
\hline Detected intracranial hypert & & $83(37)$ \\
\hline Pupil abnormalities & & $76(34)$ \\
\hline Dead & At ICU discharge & $67(31)$ \\
\hline & At hospital discharge & $74(33)$ \\
\hline & At 6 and 12 months & $79(35)$ \\
\hline Days in ICU (median, interqu & e range) & $15(7-26)$ \\
\hline Days in hospital (median, in & uartile range) & $26(11-49)$ \\
\hline
\end{tabular}

EM: evacuable mass, GCS: Glasgow Coma Scale, ICU: Intensive Care Unit, NEM: non-evacuable mass, TCDB CT: Traumatic Coma Data Bank Computed tomography.

TCDB CT was grouped in two groups: one best TCDB CT scan classification type I, II and evacuable mass (EM) and the other worst TCDB CT scan type III IV and non-evacuable mass (NEM).

therapy index score was 3, with $50 \%$ of the patients ranging between 2 and 7 . The median ICU stay was 15 days (interquartile range 20).

Non-neurological complications throughout the ICU stay are shown in Table 2: sepsis occurred in $75 \%$ of the patients, respiratory infections in $68 \%$, ICU hypotension in $44 \%$, severe respiratory failure $\left(\mathrm{PaO}_{2} / \mathrm{FiO}_{2}<200\right)$ in $41 \%$ and AKI in $8 \%$. Vasoactive drugs were used in $96 \%$ of the patients with ICU hypotension. There was only one patient with previous chronic renal failure, which was not included as AKI. The univariate analysis of the
Table 2 Non-neurological complications.

\begin{tabular}{|c|c|c|}
\hline & Variables & n (\%) \\
\hline \multirow[t]{5}{*}{ Respiratory } & Respiratory infections & $152(68)$ \\
\hline & Atelectasis & $47(21)$ \\
\hline & ARDS & $20(9)$ \\
\hline & $\mathrm{PaO}_{2} / \mathrm{FiO}_{2}<200$ & $92(41)$ \\
\hline & $\mathrm{PaO}_{2} / \mathrm{FiO}_{2} 200-300$ & $94(42)$ \\
\hline \multirow[t]{4}{*}{ Cardiovascular } & Hypotension & $99(44)$ \\
\hline & Hypertension & $28(12)$ \\
\hline & Arrhythmias & $25(11)$ \\
\hline & Dopamine, dobutamine or norepinephrine & $156(70)$ \\
\hline \multirow[t]{6}{*}{ Infection } & Sepsis & $169(75)$ \\
\hline & Septic shock & $13(6)$ \\
\hline & AKI & $17(8)$ \\
\hline & Abdominal complications & $40(18)$ \\
\hline & Electrolytical complications & $48(21)$ \\
\hline & Bleeding complications & $60(27)$ \\
\hline Non-neurosur & $\begin{array}{l}\text { jical surgery (traumatic, digestive, maxillar or } \\
\text { plastic) }\end{array}$ & $62(28)$ \\
\hline
\end{tabular}

AKI: acute kidney injury, ARDS: acute respiratory distress syndrome, $\mathrm{PaO}_{2} / \mathrm{FiO}_{2}$ : arterial oxygen pressure/oxygen inspired fraction ratio.

Respiratory infections: aspiration, tracheobronchitis and pneumonia were grouped, Non-neurosurgical surgery: traumatic, digestive, maxillar or plastic surgery.

non-neurological complications showed that hypotension, severe respiratory failure, septic shock, AKI, bleeding complications and non-neurological surgery were prognostic factors related to hospital mortality (Table 3). A multivariate regression analysis was performed for hospital mortality and GOS at one year post-TBI, taking into account variables with clinical relevance (age), variables related to TBI severity [(initial GCS (divided into GCS 3 to 5 and GCS 6 to 8), first CT scan (TCDB) and the presence of intracranial hypertension) and non-neurological complications that were statistically significant in the univariate analysis. The multivariate analysis showed that the worst outcome at one year was independently associated with age, initial GCS 3 to 5, worst TCDB first CT scan and the presence of intracranial hypertension but not AKI (Table 4). The multivariate analysis showed that hospital mortality was independently associated with an initial GSC 3 to 5, a worst TCDB first CT scan, the presence of intracranial hypertension and AKI (Table 5). Neither multiple trauma nor chest trauma was independently associated with higher mortality or worse outcome. Seventeen patients $(8 \%)$ developed AKI and 13 of them (76\%) died. In 10 of the 13 patients (77\%) death occurred after day 7 of ICU admission and in 4 of 13 renal replacement techniques had been used.

The specific effect of ICU hypotension, severe respiratory failure or AKI on outcome was also assessed in a multivariate regression model that included age, initial 
Table 3 Non-neurological complications associated to hospital mortality.

\begin{tabular}{|c|c|c|c|c|}
\hline & Variables & $\begin{array}{c}\text { Deaths } \\
74(33 \%) \\
n(\%)\end{array}$ & $\begin{array}{c}\text { Survive } \\
150(67 \%) \\
\text { n (\%) }\end{array}$ & $P$ \\
\hline \multirow[t]{5}{*}{ Respiratory } & Respiratory infection & $45(30)$ & $107(70)$ & NS \\
\hline & Atelectasis & $11(23)$ & $36(77)$ & NS \\
\hline & ARDS & $18(90)$ & $2(10)$ & $<0,01$ \\
\hline & $\mathrm{PaO}_{2} / \mathrm{FiO}_{2}<200$ & $43(47)$ & $49(53)$ & $<0,05$ \\
\hline & $\mathrm{PaO}_{2} / \mathrm{FiO}_{2} 200-300$ & $21(22)$ & $73(78)$ & $<0,05$ \\
\hline \multirow[t]{4}{*}{ Cardiovascular } & Hypotension & $50(51)$ & $49(49)$ & $<0,05$ \\
\hline & Hypertension & $7(25)$ & $21(75)$ & NS \\
\hline & Arrhythmias & $12(48)$ & $13(52)$ & NS \\
\hline & Dopamine, dobutamine or norepinephrine & $63(40)$ & $93(60)$ & $<0,05$ \\
\hline \multirow[t]{7}{*}{ Infection } & Sepsis & $53(31)$ & $116(69)$ & NS \\
\hline & Septic shock & $11(85)$ & $2(15)$ & $<0,05$ \\
\hline & AKI & $13(76)$ & $4(24)$ & $<0,05$ \\
\hline & Abdominal complications & $32(30)$ & $76(70)$ & NS \\
\hline & Electrolytical complications & $18(38)$ & $29(62)$ & NS \\
\hline & Bleeding complications & $30(50)$ & $30(50)$ & $<0,05$ \\
\hline & Non-neurosurgical surgery & $13(21)$ & $48(79)$ & $<0,05$ \\
\hline
\end{tabular}

AKI: acute kidney injury, ARDS: acute respiratory distress syndrome, $\mathrm{PaO}_{2} / \mathrm{FiO}_{2}$ : arterial oxygen pressure/oxygen inspired fraction ratio. Respiratory infections: aspiration, tracheobronchitis and pneumonia were grouped.

GCS, initial CT scan (TCDB), the presence of intracranial hypertension, the two other non-neurological complication(sepsis and respiratory infections) and their interactions. The presence of AKI regardless of GCS multiplied the risk of death 6.17 times with $95 \%$ CI of 1.37 to $27.78(P<0.02)$ and ICU hypotension in patients with low initial GCS (3 to 5 ) significantly increased the risk of death (4.28 times with $95 \% \mathrm{CI}$ of 1.37 to $27.78, P$ $<0.05$ ) (Table 6).

To estimate the effect of initial GCS on the development of non-neurological complications a multivariate regression analyzed the interactions between these conditions, finding a single interaction, low initial GCS (3 to 5), multiplied the risk of developing ICU hypotension 3.37 times $(P<0.005)$ (Table 6), suggesting that the latter condition was related to the neurological situation.

Finally, we also observed the impact of non-neurological complications in the ICU stay of surviving patients with severe TBI. The ICU stay (median (interquartile range)) in surviving patients was longer when

Table 4 Logistic regression backward stepwise for worse outcome at one year.

\begin{tabular}{lccc}
\hline Variable & OR & IC 95\% & P value \\
\hline Age & 1.03 & $1.01-1.06$ & 0.007 \\
GCS 3-5 & 3.26 & $1.36-7.89$ & 0.008 \\
Worst TCDB first CT scan & 3.05 & $1.15-8.12$ & 0.025 \\
Intracranial hypertension & 3.83 & $1.72-8.53$ & 0.001 \\
\hline
\end{tabular}

GCS: Glasgow Coma Scale, IC 95\%: 95\% confidence interval for the OR, OR: odds ratio, TCDB CT: traumatic coma data bank computed tomography. Worst TCDB CT scan referring to type III, IV and non-evacuable mass. hypotension $(16(17)$ versus 30 (27) days, $P<0.01)$, severe respiratory failure $(16(20)$ versus $25(28)$ days, $P$ $<0.01)$ and AKI $(18$ (20) versus 39 (39) days, $P<0.05)$ were present.

\section{Discussion}

The present study found that non-neurological complications were frequent during the ICU stay in a cohort of patients with severe TBI. We found some differences vis-à-vis other studies with regard to non-neurological conditions leading to worse prognosis. Hypotension, pneumonia, infectious complications and coagulation dysfunction have been associated with an unfavorable outcomes $[1,2,4,17,18]$ but in our study only AKI and hypotension in low GCS contributed independently to increasing hospital mortality together with the TBI severity variables (low initial GCS, first worst CT and intracranial hypertension).

AKI has been considered an uncommon non-neurological complication of severe TBI and is not associated

Table 5 Logistic regression backward stepwise for mortality.

\begin{tabular}{lccc}
\hline Variable & OR & IC 95\% & P value+ \\
\hline GCS 3-5 & 2.47 & $1.03-5.93$ & 0.043 \\
Worst TCDB first CT scan & 3.69 & $1.43-9.51$ & 0.007 \\
Intracranial hypertension & 10.18 & $3.85-26.89$ & 0.000 \\
Renal failure & 7.12 & $1.58-31.98$ & 0.010 \\
\hline
\end{tabular}

GCS: Glasgow Coma Scale, IC 95\%: 95\% confidence interval for the OR, OR: odds ratio, TCDB CT: traumatic coma data bank computed tomography. Worst TCDB CT scan referring to type III, IV and non-evacuable mass. 
Table 6 Adjusted odds ratio for predictors of mortality and adjusted odds ratio for predictors of ICU hypotension in our cohort.

\begin{tabular}{llccc}
\hline & Variable & OR & IC 95\% & $\begin{array}{c}\boldsymbol{P} \\
\text { value }\end{array}$ \\
\hline Mortality & ICU hypotension with low & 4.28 & $1.22-15.07$ & 0.024 \\
& GCS 3-5 & & & \\
& ICU hypotension with high & 0.13 & $0.01-02.33$ & 0.167 \\
& GCS 6-8 & & & \\
& Severe respiratory failure & 1.39 & $0.57-03.35$ & 0.467 \\
& Renal failure & 6.17 & $1.37-27.78$ & 0.018 \\
& GCS 3-5 & 3.37 & $1.66-6.82$ & 0.001 \\
ICU & & & & \\
hypotension & & & &
\end{tabular}

GCS: Glasgow Coma Scale, IC 95\%: 95\% confidence interval for the OR, ICU: intensive care unit, OR: odds ratio.

with increased mortality in these patients $[3,4,19]$. In our study, the incidence was $8 \%$, similar to a recent study in which AKI was defined by the Risk, Injury, Failure, Loss, and End-stage Kidney (RIFLE) classification and associated with age and higher Acute Physiology and Chronic Health Evaluation (APACHE) III score [20]. The change in renal function from baseline is now considered a better measure of renal injury than single serum creatinine cutoff measurements [20,21]; we applied the latter in our study, which was conducted before the introduction of the RIFLE classification for acute kidney injury evaluation. The similarity in the incidence of AKI with the two assessment methods suggests that the inclusion of patients at an early stage of renal dysfunction did not account for the differences in identifying renal injury as a non-neurological risk factor for mortality in severe TBI. In our study, 13 of 17 patients with AKI (76\%) died. In 10 of the 13 patients (77\%) death occurred after day 7 of ICU admission. AKI may be related to hypotension during ICU, although in this study it was independently associated with hospital mortality. Improvements in neurological and non-neurological monitoring and management in the ICU during these years might contribute to decrease this complication. Restoring effective circulating volume, reducing renal injury from rhabdomyolysis and avoiding nephrotoxic drugs may prevent AKI initially [22], but larger series are needed to analyze risk factors and treatment of AKI in recent severe TBI patients, probably related to multiple organ failure.

Hypotension, both at admission and during the ICU stay, has been associated with poor prognosis in patients with severe TBI $[17,18]$, so that we analyzed accurately. Duration of hypotension has also been considered one of the worst prognostic factors in these patients $[1,18]$. In our study, hypotension at some point during the ICU stay was frequent $(44 \%)$. However, in contrast to other studies $[3,5]$, it was not found to be an independent risk factor for mortality, although it increased mortality in patients with low GCS. Patients with low GCS (3 to 5) show global brain, brainstem or reticular system damage [23], which may involve the dysfunction of systemic homeostasis. This leads to non-neurological neurogenic dependent complications, which are difficult to distinguish because of the multiple conditions that these patients present, including neurogenic myocardial dysfunction and neurogenic pulmonary edema. The etiological hypothesis is that catecholamine release leads to these cardiopulmonary abnormalities. Dysregulated inflammatory mechanisms also appear to play a role in the development of the multiple organ dysfunction syndrome [5]. In our study, neurogenic causes appear to cause the hypotension that increases mortality in patients with low GCS. Despite using vasoactive drugs, a more aggressive resuscitation of patients who are at risk of hypotension, to improve outcome, requires further investigation. The bad neurological prognosis of these patients may be a limitation to using more aggressive life-sustaining therapies during their ICU stay.

Other complications, such as respiratory problems, were also frequently observed in patients with severe TBI in this study. Pneumonia was common (42\%), as in other studies $[3,4,24]$, but was not associated with increased mortality. Ventilator-associated pneumonia does not appear to raise in-hospital mortality in patients with severe TBI, but it prolongs mechanical ventilation, ICU and hospital length of stay, and increases the need for tracheostomy [25-27]. Severe respiratory failure occurred in $41 \%$ of patients, similar to another study [5]. Moderate and severe respiratory failure are poor prognostic factors [28-30], but in other studies they have not been associated with increased hospital mortality [19]. In the study by Zygun et al. neither SOFAdefined nor MOD-defined respiratory failure was significantly associated with increased hospital mortality [19]. In the study by Bratton et al. acute lung injury (ALI), $\mathrm{PaO}_{2} / \mathrm{FiO}_{2}<300$ was associated with the global severity of head injury (lower GCS scores) but not with specific anatomic lesions diagnosed by cranial CT scans [28]. In our study, severe respiratory failure was not independently associated with mortality, but it increased ICU stay. The measures proposed to prevent respiratory complications are: prevention of lung collapse and consolidation, prevention of lung infection, and acceleration of weaning from mechanical ventilation in the ICU [31]. The use of prone position, positive end-expiratory pressure (PEEP) and recruitment maneuvers have proved effective in improving tissue oxygenation with minimal negative effects of intracranial pressure and cerebral blood flow. Accurate monitoring of the physiologic cerebral function is warranted to minimize the possible negative effects on the brain induced by the maneuvers themselves [31-33]. Recently analyzed ventilator care 
bundles may be useful to prevent ventilator-associated pneumonia [34].

Intracranial hypertension is a poor prognostic factor in patients with severe TBI $[1,18,35-39]$. The presence of multiple trauma was not associated with mortality in this study. SOFA and MOD scales have been used to analyze non-neurological complications $[5,6,19]$. In one study, intracranial hypertension had higher maximum SOFA and delta SOFA, and there was a tendency for lower GCS to present higher maximum SOFA and delta SOFA which was not subsequently confirmed with the assessment of MOD [6]. However, the same authors found that the SOFA scoring system had superior discriminative ability and a stronger association with outcome than MOD with regard to hospital mortality and unfavorable neurological outcome [19]. In another study, patients with acute brain injury with GCS $<9$ had a greater incidence of sepsis, respiratory failure and need for vasopressor therapy than those with GCS > 8 [40]. However, the relationship between non-neurological organ dysfunction and TBI severity has not always been demonstrated [7]. In our study, mortality depended mainly on the TBI initial severity (low GCS 3 to 5 and worst CT scan); as in previous studies, cardiovascular, respiratory and infectious problems were the most frequent non-neurological complications $[3-5,19,40]$, but only AKI and hypotension in the low GCS group were independently associated with higher mortality.

This study has some limitations. This study was done in a single center. The definitions of non-neurological complications are not standardized; although a recent study tried to standardize data collection in TBI they did not define non-neurological complications [41]. The complications were associated with mortality, but each insult was not collected individually, so the particular impact of each one in secondary brain damage could not be evaluated. The episodes of hypotension were recorded from the first day of admittance in the ICU until the day of discharge, therefore the episodes could have appeared at any time during the period between admittance and discharge of the patients. Nor were the severity and timing of non-neurological complications recorded. However, it has been shown previously that time to development of these complications does not influence the mortality of patients with severe TBI [5], but the knowledge of the timing of these complications would be helpful to determine if these complications occurred in a pre-terminal phase or not. Withdrawal of life-sustaining therapies was not recorded.

\section{Conclusions}

In summary, low initial GCS, first CT scan and intracranial hypertension are known neurological variables that determine mortality in severe TBI patients. AKI was the only non-neurological complication associated with ICU mortality. These findings add to previous studies that showed that non-neurological complications increase length of stay and morbidity in the ICU, but do not increase mortality, with the exception of AKI and hypotension in low GCS (3 to 5).

\section{Key messages}

- GCS 3 to 5, first CT scan and intracranial hypertension are neurological variables that determine mortality in severe TBI patients.

- AKI and the association of low GCS with hypotension were the non-neurological complications independently associated with ICU mortality.

- Non-neurological complications increase length of stay and morbidity in ICU, but do not increase mortality.

\section{Abbreviations}

AKI: acute kidney injury; ALl: acute lung injury; APACHE: Acute Physiology and Chronic Health Evaluation; ARDS: Acute Respiratory Distress Syndrome; AST: aspartate amino transferase; Cl: confidence interval; CPP: cerebral perfusion pressure; CT: computed tomography; GCS: Glasgow Coma Scale; GOS: Glasgow Outcome Scale; ICP: intracranial pressure; MOD: multiple organ dysfunction; PEEP: positive end-expiratory pressure; RIFLE: Risk: Injury: Failure: Loss: and End-stage Kidney; SBP: systolic blood pressure; SIADH: Syndrome of Inappropriate Antidiuretic Hormone Secretion; SOFA: Sequential Organ Failure Assessment; SRF: severe respiratory failure; TBI: traumatic brain injury; TCDB: Traumatic Coma Data Bank.

\section{Author details}

'Intensive Care Unit, Hospital Universitari de Bellvitge, Feixa Llarga s/n, L'Hospitalet de Llobregat-08907, Barcelona, Spain. ²Departament de Ciències Fisiològiques II, Universitat de Barcelona, Feixa Llarga s/n, L'Hopitalet de Llobregat-08907, Barcelona, Spain. ${ }^{3}$ Intensive Care Unit, Hospital Universitari Germans Trias i Pujol, Carretera de Canyet s/n, Badalona-08916, Barcelona, Spain. ${ }^{4}$ Institut d'Investigació Biomèdica de Bellvitge (IDIBELL), Feixa Llarga s/ n, L'Hopitalet de Llobregat-08907, Barcelona, Spain.

\section{Authors' contributions}

LC and JV conceived of the study and participated in its design. LC, JV and $\mathrm{JH}$ collected data. PM and CJ performed the statistical analysis. RM participated in the study coordination and helped to draft the manuscript. All authors read and approved the final manuscript.

\section{Competing interests}

The authors declare that they have no competing interests.

Received: 1 October 2011 Revised: 15 November 2011

Accepted: 12 March 2012 Published: 12 March 2012

\section{References}

1. Andrews PJ, Sleeman DH, Statham PF, McQuatt A, Corruble V, Jones PA, Howells TP, McMillan CS: Predicting recovery in patients suffering from traumatic brain injury by using admission variables and physiological data: a comparison between decision tree analysis and logistic regression. J Neurosurg 2002, 97:326-336.

2. Perel P, Arango M, Clayton T, Edwards P, Komolafe E, Poccock S, Roberts I, Shakur H, Steyerberg E, Yutthakasemsunt S: Predicting outcome after traumatic brain injury: practical prognostic models based on large cohort of international patients. BMJ 2008, 336:425-429.

3. Piek J, Chesnut RM, Marshall LF, van Berkum-Clark M, Klauber MR, Blunt BA, Eisenberg HM, Jane JA, Marmarou A, Foulkes MA: Extracranial complications of severe head injury. J Neurosurg 1992, 77:901-907. 
4. Schirmer-Mikalsen K, Vik A, Gisvold SE, Skandsen T, Hynne H, Klepstad P: Severe head injury: control of physiological variables, organ failure and complications in the intensive care unit. Acta Anaesthesiol Scand 2007 51:1194-1201.

5. Zygun DA, Kortbeek JB, Fick GH, Laupland KB, Doig CJ: Non-neurologic organ dysfunction in severe traumatic brain injury. Crit Care Med 2005, 33:654-660.

6. Zygun DA, Doig CJ, Gupta AK, Whiting G, Nicholas C, Shepherd E, ConwaySmith C, Menon DK: Non-neurological organ dysfunction in neurocritical care. J Crit Care 2003, 18:238-244.

7. Zygun D: Non-neurological organ dysfunction in neurocritical care: impact on outcome and etiological considerations. Curr Opin Crit Care 2005, 11:139-143.

8. Lim HB, Smith M: Systemic complications after head injury: a clinical review. Anaesthesia 2007, 62:474-482.

9. Corral L, Ventura JL, Herrero Jl, Monfort JL, Juncadella M, Gabarros A, Bartolome C, Javierre C, Garcia-Huete L: Improvement in GOS and GOSE scores 6 and 12 months after severe traumatic brain injury. Brain Inj 2007, 21:1225-1231.

10. Genarelli TA, Spielman GM, Langfitt TW, Gildenberg PL, Harrington T, Jane JA, Marshall LF, Miller JD, Pitts LH: Influence of type of intracranial lesion on outcome from severe head injury. J Neurosurg 1982, 56:26-32.

11. Maas Al, Dearden M, Teasdale GM, Braakman R, Cohadon F, lannotti F, Karimi A, Lapierre F, Murray G, Ohman J, Persson L, Servadei F, Stocchetti N, Unterberg A: EBIC-guidelines for management of severe head injury in adults. European Brain Injury Consortium. Acta Neurochir (Wien) 1997, 139:286-294.

12. Maset AL, Marmarou A, Ward JD, Choi S, Lutz HA, Brooks D, Moulton RJ, DeSalles A, Muizelarr JP, Turner H: Pressure-volume index in head injury. J Neurosurg 1987, 67:832-840.

13. Bernard GR, Artigas A, Brigham KL, Carlet J, Falke K, Hudson L, Lamy M, LeGall JR, Morris A, Spragg R: The American-European Consensus Conference on ARDS. Definitions, mechanisms, relevant outcomes, and clinical trial coordination. Am J Respir Crit Care Med 1994, 149:818-824.

14. Bone RC, Balk RA, Cerra FB, Dellinger RP, Fein AM, Knaus WA, Schein RM, Sibbald WJ: Definitions for sepsis and organ failure and guidelines for the use of innovative therapies in sepsis. The ACCP/SCCM Consensus Conference Committee. American College of Chest Physicians/Society of Critical Care Medicine. Chest 1992, 101:1644-1655.

15. Harrigan MR: Cerebral salt wasting syndrome: a review. Neurosurgery 1996, 38:152-160.

16. Corral L, Herrero Jl, Monfort JL, Ventura JL, Javierre CF, Juncadella M, GarciaHuete L, Bartolome C, Gabarros A: First CT findings and improvement in GOS and GOSE scores 6 and 12 months after severe traumatic brain injury. Brain Inj 2009, 23:403-410.

17. Chesnut RM, Marshall SB, Piek J, Blunt BA, Klauber MR, Marshall LF: Early and late systemic hypotension as a frequent and fundamental source of cerebral ischemia following severe brain injury in the Traumatic Coma Data Bank. Acta Neurochir Suppl (Wien) 1993, 59:121-125.

18. Marmarou A, Anderson RL, Ward JD, Choi SC, Young HF, Eisenberg HM, Foulkes MA, Marshall LF, Jane JA: Impact of ICP instability and hypotension on outcome in patients with severe head trauma. $J$ Neurosurg 1991, 75:S59-S66.

19. Zygun D, Berthiaume L, Laupland K, Kortbeek J, Doig C: SOFA is superior to MOD score for the determination of non-neurologic organ dysfunction in patients with severe traumatic brain injury: a cohort study. Crit Care 2006, 10:R115.

20. Moore EM, Bellomo R, Nichol A, Harley N, Macisaac C, Cooper DJ: The incidence of acute kidney injury in patients with traumatic brain injury. Ren Fail 2010, 32:1060-1065.

21. Ricci Z, Cruz D, Ronco C: The RIFLE criteria and mortality in acute kidney injury: a systematic review. Kidney Int 2008, 73:538-546.

22. Davenport A: Management of acute kidney injury in neurotrauma. Hemodial Int 2010, 14(Suppl 1):S27-S31.

23. Laureys S, Owen AM, Schiff ND: Brain function in coma, vegetative state, and related disorders. Lancet Neurol 2004, 3:537-546.

24. Bronchard R, Albaladejo P, Brezac G, Geffroy A, Seince PF, Morris W, Branger C, Marty J: Early onset pneumonia: risk factors and consequences in head trauma patients. Anesthesiology 2004, 100:234-239.

25. Mascia L, Zavala E, Bosma K, Pasero D, Decaroli D, Andrews P, Isnardi D, Davi A, Arguis MJ, Berardino M, Ducati A, Brain IT group: High tidal volume is associated with the development of acute lung injury after severe brain injury: an international observational study. Crit Care Med 2007, 35:1815-1820

26. Zygun DA, Zuege DJ, Boiteau PJ, Laupland KB, Henderson EA, Kortbeek JB, Doig $C J$ : Ventilator-associated pneumonia in severe traumatic brain injury. Neurocrit Care 2006, 5:108-114.

27. Rincon-Ferrari MD, Flores-Cordero JM, Leal-Noval SR, Murillo-Cabezas F, Cayuelas A, Munoz-Sanchez MA, Sanchez-Olmedo J: Impact of ventilatorassociated pneumonia in patients with severe head injury. J Trauma 2004, 57:1234-1240.

28. Bratton SL, Davis RL: Acute lung injury in isolated traumatic brain injury. Neurosurgery 1997, 40:707-712.

29. Holland MC, Mackersie RC, Morabito D, Campbell AR, Kivett VA, Patel R, Erickson VR, Pittet JF: The development of acute lung injury is associated with worse neurologic outcome in patients with severe traumatic brain injury. J Trauma 2003, 55:106-111.

30. Kemp CD, Johnson JC, Riordan WP, Cotton BA: How we die: the impact of nonneurologic organ dysfunction after severe traumatic brain injury. Am Surg 2008, 74:866-872.

31. Pelosi $P$, Severgnini $P$, Chiaranda M: An integrated approach to prevent and treat respiratory failure in brain-injured patients. Curr Opin Crit Care 2005, 11:37-42.

32. Koutsoukou A, Perraki H, Raftopoulou A, Koulouris N, Sotiropoulou C, Kotanidou A, Orfanos S, Roussos C: Respiratory mechanics in braindamaged patients. Intensive Care Med 2006, 32:1947-1954.

33. Mascia L, Grasso S, Fiore T, Bruno F, Berardino M, Ducati A: Cerebropulmonary interactions during the application of low levels of positive end-expiratory pressure. Intensive Care Med 2005, 31:373-379.

34. Rello J, Chastre J, Cornaglia G, Masterton R: A European care bundle for management of ventilator-associated pneumonia. J Crit Care 2011, 26:3-10.

35. Fearnside MR, Cook RJ, McDougall P, McNeil RJ: The Westmead Head Injury Project outcome in severe head injury. A comparative analysis of pre-hospital, clinical and CT variables. Br J Neurosurg 1993, 7:267-279.

36. Miller JD: Significance and management of intracranial hypertension in head injury. In Intracranial Pressure. Edited by: Ishii S, Nagai H, Brock M. Berlin: Springer-Verlag; 1983:44-55

37. Narayan RK, Greenberg RP, Miller JD, Enas GG, Choi SC, Kishore PR, Selhorst JB, Lutz HA, Becker DP: Improved confidence of outcome prediction in severe head injury. A comparative analysis of the clinical examination, multimodality evoked potentials, CT scanning, and intracranial pressure. J Neurosurg 1981, 54:751-762.

38. Stocchetti N, Rossi S, Buzzi F, Mattioli C, Paparella A, Colombo A: Intracranial hypertension in head injury: management and results. Intensive Care Med 1999, 25:371-376.

39. Vik A, Nag T, Fredriksli OA, Skandsen T, Moen KG, Schirmer-Mikalsen K, Manley GT: Relationship of "dose" of intracranial hypertension to outcome in severe traumatic brain injury. J Neurosurg 2008, 109:678-684

40. Mascia L, Sakr Y, Pasero D, Payen D, Reinhart K, Vincent JL: Extracranial complications in patients with acute brain injury: a post-hoc analysis of the SOAP study. Intensive Care Med 2008, 34:720-727.

41. Maas Al, Harrison-Felix CL, Menon D, Adelson D, Balkin T, Bullock R, Engel DC, Gordon W, Langlois-Oman J, Lew HI, Robertson C, Temkin N, Valadka A, Verfaellie M, Wainwright M, Wright DW, Schwab K: Standardizing Data Collection in Traumatic Brain Injury. J Neurotrauma 2011, 28:177-187.

doi:10.1186/cc11243

Cite this article as: Corral et al:: Impact of non-neurological complications in severe traumatic brain injury outcome. Critical Care 2012 16:R44. 